\title{
Deformations and cyclic fatigue resistance of nickel-titanium instruments inside a sequence
}

\author{
Gianluca Gambarini, MD,DDS 1 \\ Gianluca Plotino, DDS, PhD ${ }^{1}$ \\ Lucila Piasecki, DDS ${ }^{2}$ \\ Dina Al-Sudani, DDS ${ }^{3}$ \\ Luca Testarelli, DDS, PhD1 \\ Gianpaolo Sannino, MD, DDS 4
}

\footnotetext{
${ }^{1}$ Endodontics Unit, Department of Oral and Maxillofacial Sciences, "Sapienza" University of Rome, Italy 2 PUC University, Curitiba, Brasil

${ }^{3}$ Department of Restorative Dental Science, College of Dentistry, King Saud University, Riyadh, Saudi Arabia

4 University of Rome II, Tor Vergata, Italy
}

There are no disclosures for the present study.

Corresponding author:

Gianluca Gambarini

Department of Endodontics Unit

Oral and Maxillo-facial Sciences

"Sapienza" University of Rome

Via Calabria, 25

00187 Rome, Italy

E-mail: ggambarini@gmail.com

\section{Summary}

Aim. To compare the effect of brushing motion on torsional and cyclic fatigue resistance of TF Adaptive instruments after clinical use.

Methods. 20 packs of TFA small sequence (SybronEndo, Orange, CA, USA) were used for this study and divided into two groups. Each instrument prepared one resin tooth, consisting in 4 canals with a complex anatomy. In group A, no brushing motion was performed. In group B, after the green instrument reached the working length, brushing motion with circumferential filing was performed for 15 seconds in each canal (overall 1 minute). All the instruments were then subjected to cyclic fatigue test and mean values and standard deviation for time to fracture were evaluated. Data were subjected to one-way analysis of variance and Bonferroni $t$-test procedure with a significance set at $P<0.05$.

Results. No instruments were broken during preparation of root canals. Two TF Adaptive green and 5 yellow showed unwinding after intracanal clinical use. No statistically significant dif- ferences were found between green instruments of both groups $(P>0.05)$, while a statistically significant difference was found between the yellow instruments $(P<0.05)$, with group $B$ showing an higher resistance to cyclic fatigue.

Conclusions. A prolonged passive brushing motion did not adversely affected mechanical resistance of the instrument used for this purpose. Resistance to both deformations and cyclic fatigue of the second instrument within the TFA small sequence was enhanced by the coronal flaring provided by the brushing action of the first instrument used.

Key words: nickel-titanium, brushing action, deformations, cyclic fatigue.

\section{Introduction}

In the last decades the use of nickel-titanium (NiTi) rotary instruments has become the most effective and popular method amongst endodontists for shaping root canals, due to their greater elasticity, strength and cutting efficiency (1). Despite these advantages, fracture of $\mathrm{NiTi}$ rotary instruments caused by torsional stress and/or cyclic fatigue has remained a primary concern in endodontics practice, because they tend to break unexpectedly during intracanal use (2). Following the introduction of NiTi alloy in endodontics, manufacturers have frequently changed the cross-sectional design and geometrical features of instruments to improve both torsional and cyclic fatigue resistance $(3,4)$. Since 2007 , new alloys and new manufacturing processes were adopted to optimize the microstructure of $\mathrm{NiTi}$, basically through innovative thermomechanical processing (5). NiTl instruments produced with these technologies (M-wire, CM wire or Twisted Files) showed better properties in terms of flexibility and resistance to mechanical stress when compared to traditional NiTi alloy and processing (5-7).

More recently, the use of single-file $\mathrm{NiTi}$ reciprocating instruments have been advocated as a simple, safe alternative to rotary instrumentation techniques (8). Current literature data show that reciprocating motion can extend both torsional and cyclic fatigue resistance of $\mathrm{NiTi}$ instruments when compared to continuous rotation, by reducing instrumentation stress (912). Despite this improvement, the accumulation of all instrumentation stress on one single-file may still be high, and consequently new reciprocating movements were developed to be used within a sequence, such as TF Adaptive (TFA) $(13,14)$. 
Other clinical factors, mainly related to individual skill, sensitivity and operative choice, also affect torsional and cyclic fatigue resistance of NiTi instruments: the applied pressure, the tendency to force the instrument apically, the use of torque control motors, prolonged re-use, the creation of a glide path (15) and so on. It has been shown that resistance to fatigue is related to instrumentation time, being significantly reduced after multiple clinical use (16).

Traditionally, NiTi instruments are used as reamers, while progressing to the working length, More recently, the use of a brushing motion in addition to the traditional reaming action was proposed to improve safety and efficiency of $\mathrm{NiTi}$ instrumentation (17). The benefit of the brushing action is not only to enhance the amount of canal walls touched by the file, but also to provide more coronal enlargement for a safer progression of instruments within a sequence $(18,19)$.

Since the brushing motion increases instrumentation time, the aim of this study was to compare its effect on torsional and cyclic fatigue resistance of TFA instruments after clinical use.

\section{Material and methods}

Twenty packs of TFA small sequence (SybronEndo, Orange, CA, USA) were used for this study and randomly divided into two groups of ten each. To avoid any changes related to anatomy, twenty plastic first maxillary molar $3 \mathrm{D}$ teeth with the same morphology (Real-T Endo, Aca Dental, Inc., Overland Park, KS, USA) were used for this study as previously done (20). Each instrument prepared one tooth, consisting in 4 canals with a complex anatomy. Following the manufactures' guidelines for the TF Adaptive small sequence, a manual glide path up to a ISO size 15 was performed using the stainless-steel (SS) K-file instrument available in the package. Following the traffic light concept given by the manufacturer (http://axis.sybronendo.com/tfadaptive_confidence\#ta b6), the instrumentation was stopped at yellow, using only the first two instruments of the sequence: the green TFA instrument (tip size 20, .04 taper) followed by the red TFA instrument (tip size 25, .06 taper). All instruments were used with the patented TFA motion in a specific endodontic motor (Elements Motor, SybronEndo, Orange, CA, USA), which automatically selected the kinematics (continuous rotation or reciprocation) according to intracanal stress applied on the instrument during instrumentation. All instruments reached the working length by incremental steps (1 $\mathrm{mm}$ ) without being forced apically and the flutes were always cleaned after each $1 \mathrm{~mm}$ apical progression. Irrigation was performed with alchool every each instrument.

In group $A$, no brushing motion was performed. In group $B$, after the green instrument reached the working length, brushing motion with circumferential filing was performed for 15 seconds in each canal (overall
1 minute) to increase coronal flaring. Before any brushing motion, instruments were withdrawn $1 \mathrm{~mm}$ short of the working length, thus preventing any over engagement with the canal walls. After shaping procedures were completed all the 40 used NiTi instruments were inspected under magnification $(3 x)$ to check any sign of plastic deformation or undwinding of flutes.

All the instruments were then subjected to cyclic fatigue test using a testing device that was previously described (21-27). Briefly, all instruments were tested using the TFA motion powered by Elements motor (SybronEndo, Orange, CA, USA). After positioning the instrument into a simulated root canal with a $60^{\circ}$ angle of curvature and $5-\mathrm{mm}$ radius of curvature, as soon as rotation started timing was initiated and then stopped when instrument breakage was observed. For each instrument, the time to fracture in seconds was recorded by the same operator with a chronometer to an accuracy of 0.1 second. Since the motor automatically selects the mode of use and the reciprocating angles depending on the canal anatomy, speed and number of cycles to failure could not be precisely calculated. Mean values and standard deviation (SD) for time to fracture were evaluated. To determine any statistical difference between the groups, the data were subjected to a one-way analysis of variance. When the overall $F$ test indicated a significant difference, the multiple-comparison Bonferroni $t$ test procedure was performed to identify differences among groups. Significance was set at the $95 \%$ confidence level.

\section{Results}

No instruments were broken during preparation of root canals. Two TF Adaptive green, tip size 20 and .04 taper (one in each group $A$ and $B$ ), and 5 TF Adaptive yellow, tip size 25 and .06 taper (4 from Group A and 1 from Group B) showed unwinding after intracanal clinical use.

Results of cyclic fatigue test are reported in Table 1. No statistically significant differences were found between green instruments of both groups $(P>0.05)$, showing that one additional minute of brushing motion did not decreased fatigue resistance. A statistically significant difference was found between the yellow instruments $(P<0.05)$, with group $B$ showing an higher resistance to cyclic fatigue. These differences are attributed to coronal flaring provided by the green instrument used with a brushing motion, which reduced instrumentation stress for the next (yellow) instrument.

Table 1. Mean time to fracture in seconds (Standard Deviation) of the different instruments tested.

\begin{tabular}{lll}
\hline Instrument Size & Green (20/.04) & Yellow (25/.06) \\
\hline Group A (No Brushing) & $142(20)$ & $73(6)$ \\
Group B (Brushing) & $137(15)$ & $97(7)$ \\
\hline
\end{tabular}




\section{Discussion}

Clinical performance of $\mathrm{NiTi}$ instruments can be related to the operative techniques. It has been suggested that any NiTi instrument may be used both as a reamer cutting in advancement and with a brushing action as a hedstroem file, to improve coronal and/or circumferential flaring (19), but safety and efficiency of the proposed technique needed further assessments.

The present study demonstrates that a brushing action can be performed up to 60 seconds with minimal or no risk of increasing instrument fatigue. The green TFA instrument (tip size 20, .04 taper) which performed a brushing action for 15 seconds in each of the four canals did not showed a significant decrease of resistance to cyclic fatigue. These findings are consistent with previously published results $(17,19)$. Incidence of instrument deformation was not affected by the brushing action. The green TFA instruments were subjected to significant torsional stress while progressing to the working length, which produced undwinding of flutes of one instrument in both groups. On the contrary, no unwinding was observed while performing the brushing action, instrument blades were fully disengaged during passive brushing motion as performed in the present study. As a consequence, lateral hedstroem-like cutting resulted in much less torsional stress applied on the instrument compared to a traditional reaming-like cutting, in which blades are usually engaged.

TF Adaptive instruments were selected for the present study because the TF technology produces a NiTi alloy which is more ductile. Similarly to stainlesssteel instruments, a ductile NiTi file tends to show visible plastic deformation before breakage, when subjected to high torsional loading (28). This can be considered as a safety feature. It allows to discard NiTi instruments which have accumulated metal fatigue, reducing the risk of unexpected breakage. Shen et al. (29) showed that the tendency to show plastic deformation can vary amongst instruments, focusing the attention mainly on differences in design and not on the alloy or manufacturing process TFA instruments were also selected because of their unique motion, which has never been investigated in relation with clinical resistance to torsional and flexural fatigue.

The present study also demonstrated that increasing coronal flaring allowed a safer progression to the working length of the instrument used immediately after. In fact, the incidence of deformations (undwinding of the flutes) of the second instrument used within the TF Adaptive sequence (yellow, tip size 25, .06 taper) was higher when brushing and coronal flaring was not performed by the green instrument (tip size 20, .04 taper) previously used in the same sequence. In addition, yellow instruments of group A (no brushing motion) showed a significant lower resistance to cyclic fatigue when compared to group B in which brushing with circumferential filing had been previously performed by the green instrument.

In conclusion, based from the findings of the present study, it may be concluded that: a) the coronal flaring provided by the brushing action of the first green instrument of the TFA small sequence reduced the instrumentation stress exerted on the second instrument within the same sequence. Resistance to both torsional stress (which may cause undwinding of the flutes) and flexural stress (which may affect resistance to cyclic fatigue of used instruments) was enhanced;

b) a prolonged passive brushing motion as performed in the present study (60 seconds) did not adversely affected mechanical resistance of the instruments used for this purpose. Resistance to both torsional and flexural fatigue was not decreased.

\section{References}

1. Peters OA. Current challenges and concepts in the preparation of root canal systems: a review. J Endod. 2004;30:559-67.

2. Plotino G, Grande NM, Cordaro M, Testarelli L, Gambarini G. A review of cyclic fatigue testing of nickel-titanium rotary instruments. J Endod. 2009;35:1469-76.

3. Best S, Watson P, Pilliar R, Kulkarni GG, Yared G. Torsional fatigue and endurance limit of a size 30.06 ProFile rotary instrument. Int Endod J. 2004;37:370-3.

4. Grande NM, Plotino G, Pecci R, Bedini R, Malagnino VA, Somma F. Cyclic fatigue resistance and three-dimensional analysis of instruments from two nickel-titanium rotary systems. Int Endod J. 2006;39:755-63.

5. Gambarini G, Plotino G, Grande NM, Al-Sudani D, De Luca $M$, Testarelli L. Mechanical properties of nickel-titanium rotary instruments produced with a new manufacturing technique. Int Endod J. 2011;44:37-41.

6. Plotino G, Testarelli L, Al-Sudani D, Pongione G, Grande NM, Gambarini G. Fatigue resistance of rotary instruments manufactured using different nickel-titanium alloys: a comparative study. Odontology. 2014;102:31-5.

7. Testarelli L, Plotino G, Al-Sudani D, Vincenzi V, Giansiracusa A, Grande NM, Gambarini G. Bending properties of a new nickel-titanium alloy with a lower percent by weight of nickel. J Endod. 2011;37:1293-5.

8. Yared G. Canal preparation using only one Ni-Ti rotary instrument: preliminary observations. Int Endod J. 2008;41:339-44.

9. Kiefner $P$, Ban M, De-Deus $G$. Is the reciprocating movement per se able to improve the cyclic fatigue resistance of instruments? Int Endod J. 2013;Jul 12. doi: 10.1111/iej.12166.

10. Pedullà E, Grande NM, Plotino G, Palermo F, Gambarini G, Rapisarda E. Cyclic fatigue resistance of two reciprocating nickel-titanium instruments after immersion in sodium hypochlorite. Int Endod J. 2013;46:155-9.

11. Pedullà E, Grande NM, Plotino G, Gambarini G, Rapisarda E. Influence of continuous or reciprocating motion on cyclic fatigue resistance of 4 different nickel-titanium rotary instruments. J Endod. 2013;39:258-61.

12. Plotino G, Grande NM, Testarelli L, Gambarini G. Cyclic fatigue of Reciproc and WaveOne reciprocating instruments. Int Endod J. 2012;46:614-8.

13. Gambarini G, Gergi R, Naaman A, Osta N, Al Sudani D. Cyclic fatigue analysis of twisted file rotary $\mathrm{NiTi}$ instruments used in reciprocating motion. Int Endod J. 2012;45:802-6.

14. Gambarini G, Testarelli L, De Luca M, Milana V, Plotino G, Grande NM, Rubini AG, Al Sudani D, Sannino G. The influence of three different instrumentation techniques on the incidence of postoperative pain after endodontic treatment. Ann Stomatol. 2013;20:152-5.

15. Berutti E, Paolino DS, Chiandussi G, Alovisi M, Cantatore 
G, Castellucci A, Pasqualini D. Root canal anatomy preservation of WaveOne reciprocating files with or without glide path. J Endod. 2012;38:101-4.

16. Fife D, Gambarini G, Britto Lr. Cyclic fatigue testing of ProTaper NiTi rotary instruments after clinical use. Oral Surg Oral Med Oral Pathol Oral Radiol Endod. 2004;97:251-6.

17. Plotino G, Grande NM, Sorci E, Malagnino VA, Somma F. Influence of a brushing working motion on the fatigue life of NiTi rotary instruments. Int Endod J. 2007;40:45-51.

18. Grande NM, Plotino G, Butti A, Messina F, Pameijer CH, Somma F. Cross-sectional analysis of root canals prepared with NiTi rotary instruments and stainless steel reciprocating files. Oral Surg Oral Med Oral Pathol Oral Radiol Endod. 2007;103:120-6.

19. Gambarini G, Tucci E, Bedini R, Pecci R, Galli M, Milana V, De Luca M, Testarelli $L$. The effect of brushing motion on the cyclic fatigue of rotary nickel titanium instruments. Ann Istit Sup San. 2010;46:400-4.

20. Pedullà E, Plotino G, Grande NM, Scibilia M, Pappalardo A, Malagnino VA, Rapisarda E. Influence of rotational speed on the cyclic fatigue of Mtwo instruments. Int Endod J. 2013;Jul 23. doi: 10.1111/iej.12178.

21. Al-Sudani D, Grande NM, Plotino G, Pompa G, Di Carlo S, Testarelli L, Gambarini G. Cyclic fatigue of nickel-titanium rotary instruments in a double (S-shaped) simulated curvature. J Endod. 2012;38:987-9.

22. Gambarini G, Grande NM, Plotino G, Somma F, Garala M, De Luca M, Testarelli L. Fatigue resistance of engine-driven rotary nickel-titanium instruments produced by new manu- facturing methods. J Endod. 2008;34:1003-5.

23. Plotino G, Grande NM, Sorci E, Malagnino VA, Somma F. A comparison of cyclic fatigue between used and new Mtwo Ni-Ti rotary instruments. Int Endod J. 2006;39:716-23.

24. Plotino G, Grande NM, Cordaro M, Testarelli L, Gambarini G. Measurement of the trajectory of different NiTi rotary instruments in an artificial canal specifically designed for cyclic fatigue tests. Oral Surg Oral Med Oral Pathol Oral Radiol Endod. 2009;108:e152-6.

25. Plotino G, Grande, NM, Mazza C, Petrovic R, Testarelli L, Gambarini G. Influence of size and taper of artificial canals on the trajectory of NiTi rotary instruments in cyclic fatigue studies. Oral Surg Oral Med Oral Pathol Oral Radiol Endod. 2010;97:e60-6.

26. Plotino G, Grande NM, Cordaro M, Testarelli L, Gambarini G. Influence of the shape of artificial canals on the fatigue resistance of NiTi rotary instruments. Int Endod J. 2010;43:69-75.

27. Plotino G, Costanzo A, Grande NM, Petrovic R, Testarelli L, Gambarini G. Experimental evaluation on the influence of autoclave sterilization on the cyclic fatigue of new nickel-titanium rotary instruments. J Endod. 2012;38:222-5.

28. Wycoff RC, Berzins DW. An in vitro comparison of torsional stress properties of three different rotary nickel-titanium files with a similar cross-sectional design. J Endod. 2012; 38:1118-20.

29. Shen Y, Cheung GS, Peng B, Haapasalo M. Defects in nickel-titanium instruments after clinical use. Part 2: Fractographic analysis of fractured surface in a cohort study. J Endod. 2009;35:133-6. 